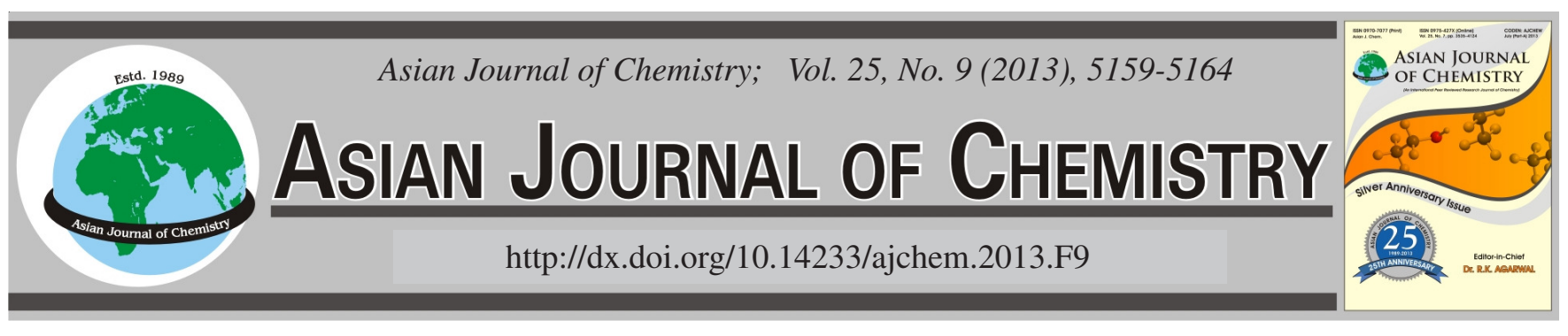

\title{
Effect of Organically Modified Layered Silicate on Degradation of Chloroprene Rubber $\dagger$
}

\author{
Jin Hyok LeE ${ }^{1,2}$, Jong Woo BAE ${ }^{1}$, Jung Soo Kim ${ }^{1}$, Yoo Seok Choi $^{3}$ and NAm Ju Jo ${ }^{2, *}$
}

\begin{abstract}
${ }^{1}$ Industrial Materials Fusion Technology Center, Korea Institute of Footwear and Leather Technology, Busan 614-100, Republic of Korea ${ }^{2}$ Department of Polymer Engineering, Pusan National University, Busan 609-735, Republic of Korea
\end{abstract}

${ }^{3}$ Department of Polymer Engineering, Pukyong National University, Busan 608-739, Republic of Korea

*Corresponding author: Fax: +82 51 6053316; Tel: +82 51 6053310; E-mail: namjujo@ pusan.ac.kr

AJC-13164

\begin{abstract}
This study examined the effect of organically modified layered silicate on the degradation of chloroprene rubber with particular focus on the nano-size and structure of organically modified layered silicate, as well as the tortuous structure of the resulting nanocomposites. Chloroprene rubber/organically modified layered silicate nanocomposites were prepared using the melt intercalation method. X-ray diffraction revealed the dispersion of organically modified layered silicate. Compared to pure organically modified layered silicate, the basal space of chloroprene rubber/organically modified layered silicate nanocomposite was shifted from $2.1 \mathrm{~nm}$ to $4.2 \mathrm{~nm}$ and the XRD peak was shifted from $3.96^{\circ}$ to $2.35^{\circ} 2 \theta$. XRD confirmed that organically modified layered silicate layers were intercalated into the chloroprene rubber matrix. Compared to the conventional filler loaded composites, the chloroprene rubber/organically modified layered silicate nanocomposite exhibited high mechanical properties. The chloroprene rubber/organically modified layered silicate nanocomposite showed 28, 43 and $43 \%$ improvement in tensile strength, tear strength and compression set, respectively, compared to the no filler-loaded chloroprene rubber composite. The change in the mechanical properties after the thermal aging test was dependent on the aspect ratio and dispersion state of the filler. Organically modified layered silicate was dispersed on the nano-level. The chloroprene rubber/organically modified layered silicate nanocomposite showed the lowest change in mechanical properties. In the modulus profile, chloroprene rubberorganically modified layered silicate showed a smaller deviation of the modulus according to the position and a lower $10 \%$ compressive modulus than chloroprene rubber-NF. Intercalation of the organically modified layered silicate layers to the chloroprene rubber matrix led to the formation of a tortuous structure. The tortuous structure hindered oxygen diffusion and decreased the degradation rate. An analysis of the oxygen permeability confirmed that the chloroprene rubber/organically modified layered silicate nanocomposite had formed a tortuous structure.
\end{abstract}

Key Words: Organically modified layered silicate, Nanocomposites, Chloroprene rubber, Gas permeability, Degradation.

\section{INTRODUCTION}

For some times, analyses of the degradation behaviour of elastomers have been an important and interesting issue. Many factors affect the degradation of the elastomer, such as temperature, light, ionizing radiation, humidity, fluids, etc. ${ }^{1}$. In these factors, oxygen was reported to be an important and effective factor in the degradation of the elastomer ${ }^{2}$. The degradation of an elastomer and predictions of their lifetimes have been studied using a range of techniques. Gillen et al..$^{3-5}$ reviewed many techniques to analyze elastomer degradation include modulus profiling, oxygen permeability, NMR, TGA and DTA. By analyzing the modulus profiling, oxygen permeability and oxygen consumption rate, Gillen et al..$^{6-11}$ also monitored the change in activation energy with temperature and predicted the life-times of the elastomers. The degradation rate of an elastomer was found to be affected directly by the oxygen diffusion rate and can be controlled effectively by controlling the oxygen diffusion rate.

An organically modified layered silicate layer has a thickness of approximately $1 \mathrm{~nm}$ and a high aspect ratio. Organically modified layered silicate has a bundle shape with aluminosilicate layers stacked on the other. Organically modified layered silicate can be intercalated and exfoliated to the elastomer and form nanocomposites ${ }^{12-14}$. Compared to carbon black or silicareinforced elastomer composites, these nanocomposites have strongly reinforced mechanical properties. Furthermore, organically modified layered silicate layers that are intercalated and exfoliated to the elastomer form a tortuous structure with improved gas barrier properties ${ }^{15-17}$.

The tortuous structure of nanocomposites would affect the degradation rate of the elastomer because the degradation

$†$ Presented to the International Rubber Conference (IRC-2012), May 21-24, 2012, Jeju, Republic of Korea 
of the elastomer is affected directly by the oxygen diffusion rate. In this study, organically modified layered silicate was dispersed to chloroprene rubber using the melt intercalation method and chloroprene rubber/organically modified layered silicate nanocomposites were formed. XRD revealed the dispersion state of the chloroprene rubber/organically modified layered silicate nanocomposites. The effect of organically modified layered silicate on the reinforcement and degradation of chloroprene rubber was compared with the conventional filler (silica, carbon black and talc)-loaded chloroprene rubber composites. The effect of organically modified layered silicate on the degradation of chloroprene rubber was observed by measuring the change in the mechanical properties after the thermal aging test and by analyzing the oxygen permeability.

\section{EXPERIMENTAL}

Chloroprene rubber S40V (DENKA, Japan) was used as the main matrix. Organically modified layered silicate was purchased from Southern Clay (USA). Silica was acquired from Rhodia(French) and carbon black was supplied by EVONIK Carbon Black Korea Co. Ltd. (Korea). Talc was purchased from KOCH Co. (Korea). The other agents used were obtained commercially.

The chloroprene rubber composites were prepared using the following method. 1) Various amount of additives and filler were mastificated with chloroprene rubber using an internal mixer for $10 \mathrm{~min}$. 2) The compounds were mixed with a crosslinking agent and accelerator on an open two-roll mill for $7 \mathrm{~min}$. 3) The compounds were vulcanized to prepare the chloroprene rubber composites at $155^{\circ} \mathrm{C}$ for the optimum vulcanization time $\left(\mathrm{t}_{90}\right)$. The optimum vulcanization time was measured using a moving disc rheometer. Nichigo Shoji Co. (Japan) model W. Table-1 lists the formulations of the prepared chloroprene rubber composites.

\begin{tabular}{lccccc}
\multicolumn{7}{c}{ TABLE-1 } & & \\
\multicolumn{5}{c}{ FORMULATION OF CHLOROPRENE COMPOSITES (phr) } \\
\hline \multicolumn{1}{c}{ Compound No. } & CR- & \multirow{2}{*}{ CR-S } & CR- & CR- & CR- \\
& NF & & CB & T & OLS \\
\hline Chloroprene & 100 & 100 & 100 & 100 & 100 \\
Filler 5 phr & 0 & Silica & HAF & Talc & OLS \\
Dibutoxyethoxyethyladipate & 5 & 5 & 5 & 5 & 5 \\
Zinc oxide & 5 & 5 & 5 & 5 & 5 \\
Magnesium oxide & 4 & 4 & 4 & 4 & 4 \\
Stearic acid & 0.5 & 0.5 & 0.5 & 0.5 & 0.5 \\
Octylated diphenylamine & 1.0 & 1.0 & 1.0 & 1.0 & 1.0 \\
Tri-methylthiourea & 1.5 & 1.5 & 1.5 & 1.5 & 1.5 \\
Tetramethyl thiuram & 0.5 & 0.5 & 0.5 & 0.5 & 0.5 \\
Monosulphide & & & & & \\
N-Cyclohexyl-2- & 0.5 & 0.5 & 0.5 & 0.5 & 0.5 \\
benzothiazole Sulfenamide & & & & & \\
\hline
\end{tabular}

Mechanical properties: An universal test machine [3345 (Q3776) Instron, U.S.A.] was used to measure the mechanical properties of all specimens. The mechanical properties were measured according to KS (Korea Standard) M 6518 and KS M 6517. The test speed was $500 \mathrm{~mm} / \mathrm{min}$. The compression set was measured using a cylinder type specimen $(20 \mathrm{~mm}$ in diameter and $10 \mathrm{~mm}$ in thickness). The initial compression ratio was $20 \%$ and the compressed specimens were aged thermally at $100{ }^{\circ} \mathrm{C}$ for $72 \mathrm{~h}$. The compression set was calculated from the thickness of recovery after thermal aging.

X-ray diffraction: X-ray diffraction (XRD, X'Pert-MPD, Philips, Netherlands) was used to analyze the organically modified layered silicate and chloroprene rubber/organically modified layered silicate nanocomposite with $\mathrm{CuK}_{\alpha}$ radiation.

Change in the mechanical properties after thermal aging test: The degradation behaviour was determined from the change in mechanical properties according to the thermal aging test. Each specimen was aged thermally for $120 \mathrm{~h}$ at $100{ }^{\circ} \mathrm{C}$ and the changes in the mechanical properties were measured by a comparison before and after the thermal aging test. A convection oven, AS-F0-05 model of A-Sung Tester Co. (Korea), was used for the thermal aging tests. The temperature deviation was $\pm 1{ }^{\circ} \mathrm{C}$ between the gauge and actual temperature.

Modulus profile after thermal aging test: The modulus profile was measured using the following steps. 1) Cylinder type specimens (20 $\mathrm{mm}$ in diameter and $10 \mathrm{~mm}$ in thickness) were used. 2) After the thermal aging test, the specimen was sliced into five pieces with a $2 \mathrm{~mm}$ thickness. 3) For each sliced piece, the $10 \%$ compressive modulus was measured.

Oxygen permeability: A gas permeability apparatus (BT3 model, TOYOSEIKI, Japan) was used to measure the oxygen permeability of all the specimens. The pressure was maintained at $0.48 \mathrm{MPa}$ on one side of the specimen sheet ( $1 \mathrm{~mm}$ in thickness and $60 \mathrm{~mm}$ in diameter) and was initially zero on the other side. The oxygen permeability was calculated from the amount of oxygen transmitted through the sheet at $40^{\circ} \mathrm{C}$, which was determined by gas chromatography.

\section{RESULTS AND DISCUSSION}

Dispersion of chloroprene rubber/organically modified layered silicate nanocomposite: The dispersion of organically modified layered silicate was observed by XRD. Fig. 1 shows XRD patterns of pure organically modified layered silicate and chloroprene rubber-organically modified layered silicate. Fig. 1(a) showed the XRD pattern of pure organically modified layered silicate. The basal spacing of pure organically modified layered silicate was $2.1 \mathrm{~nm}$ and an intense peak was observed at $3.96^{\circ} 2 \theta$. Fig. 1(b) shows the XRD pattern of chloroprene rubber-organically modified layered silicate. The basal spacing of chloroprene rubber-organically modified layered silicate was $4.2 \mathrm{~nm}$ and an intense peak was observed $2.35^{\circ} 2 \theta$. A higher order reflection (d002) was also observed. These phenomena caused by the chloroprene rubber matrix intercalated to inside the organically modified layered silicate bundles. By intercalating, the distance between each organically modified layered silicate bundle was increased. Overall, XRD confirmed the dispersion of organically modified layered silicate in the chloroprene rubber matrix on the nano-level and the formation of a chloroprene rubber/organically modified layered silicate nanocomposite.

Mechanical properties: Fig. 2 presents the results of the tensile strength and elongation. The no filler added formulation, chloroprene rubber-NF, showed the lowest tensile strength (11.1 MPa). Each filler had a different reinforcing effect. The 
tensile strength was observed in the following order: organically modified layered silicate $>$ carbon black $>$ silica $>$ talc $>$ no filler. The chloroprene rubber/organically modified layered silicate nanocomposite showed highest tensile strength (14.2 MPa). The tensile strength increased approximately $27.8 \%$ when $5 \mathrm{phr}$ organically modified layered silicate was loaded. Elongation showed the following order: organically modified layered silicate $>$ no filler $>$ silica $>$ talc $>$ carbon black. The filler loading resulted in an increase in tensile strength and decrease in elongation. On the other hand, chloroprene rubber-organically modified layered silicate showed the highest elongation (621\%). This was attributed to the effective intercalation of the organically modified layered silicate layers to the chloroprene rubber matrix on the nano-level. Fig. 3 shows the result of the tear strength. chloroprene rubber-NF showed lowest tear strength $(24.3 \mathrm{kN} / \mathrm{m})$. The tear strength was observed in the following order: organically modified layered silicate $>$ carbon black, silica $>$ talc $>$ no filler. chloroprene rubber-organically modified layered silicate showed the highest tear strength $(34.7 \mathrm{kN} / \mathrm{m})$. The tear strength increased approximately $43.3 \%$ when $5 \mathrm{phr}$ organically modified layered silicate was loaded. Fig. 4 shows the result of the compression set. Chloroprene rubber-NF showed $37.3 \%$ of the compression set. The compression set was observed in the following order: organically modified layered silicate $>$ carbon black $>$ silica $>$ talc $>$ no filler. Chloroprene rubber-organically modified layered silicate showed the lowest compression set (32.1\%). The compression set was improved approximately $13.9 \%$ when 5 phr organically modified layered silicate was loaded. An analysis of the mechanical properties confirmed that the organically modified layered silicate layers effectively intercalated into the chloroprene rubber matrix, leading to a good reinforcing effect on chloroprene rubber-organically modified layered silicate.

Change in the mechanical properties after thermal aging test: Fig. 5 shows the change in tensile strength after the thermal aging test. The tensile strength decreased after the thermal aging test because all specimens were degraded by

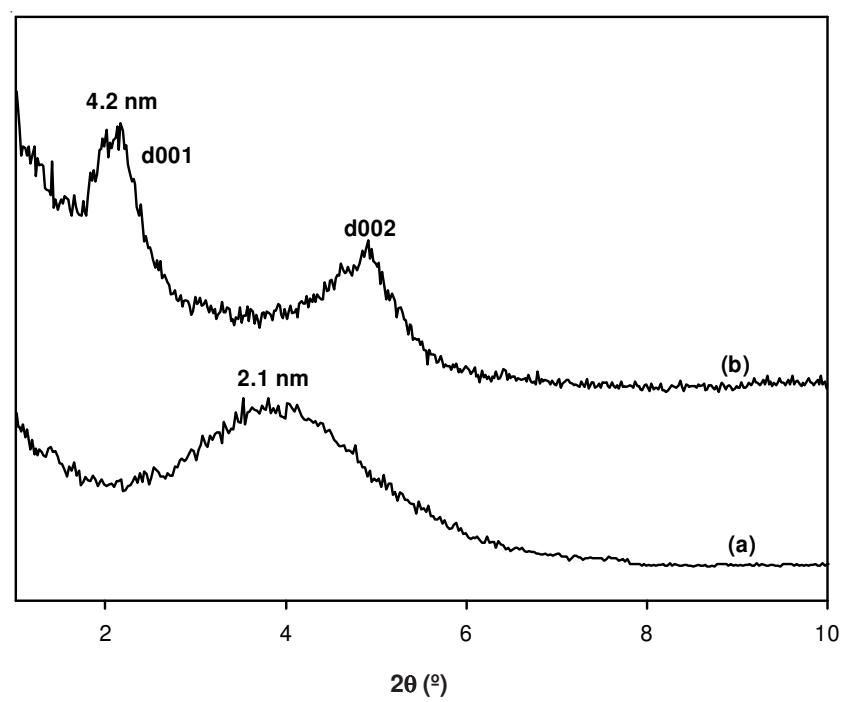

Fig. 1. XRD patterns of (a) organically modified layered silicate and (b) chloroprene rubber-organically modified layered silicate

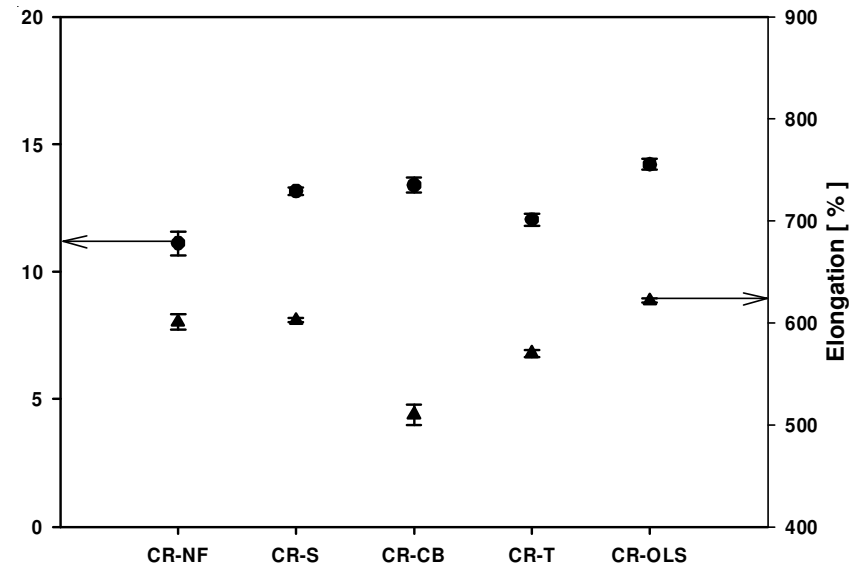

Fig. 2. Tensile strength and elongation of chloroprene rubber composites by filler type

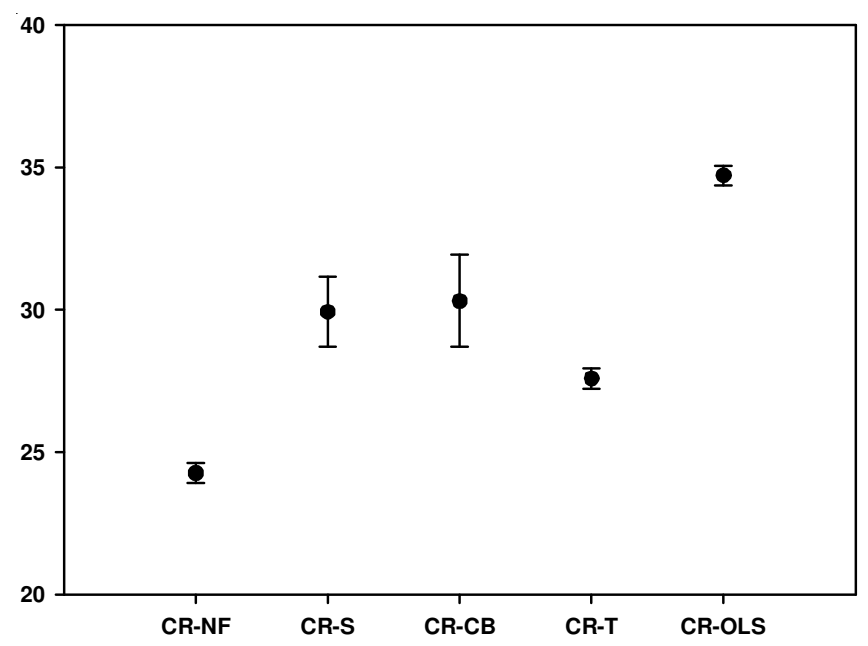

Fig. 3. Tear strength of chloroprene rubber composites by filler type

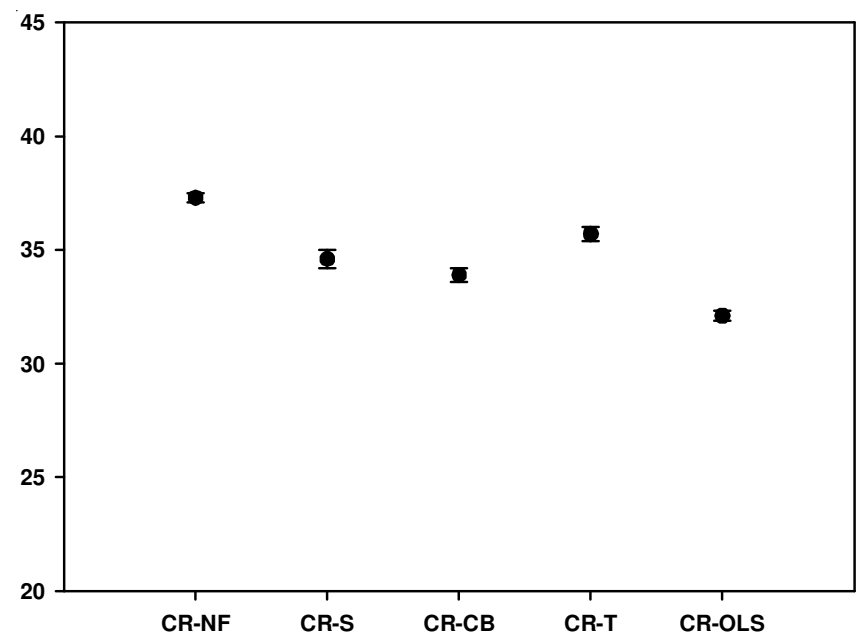

Fig. 4. Compression set of chloroprene rubber composites by filler type

oxidation of the chloroprene rubber matrix. The change in the tensile strength of chloroprene rubber-NF was $-4.1 \mathrm{MPa}$. Compared to the initial state, the tensile strength of chloroprene rubber-NF decreased approximately $36.6 \%$ after the thermal aging test. The change in tensile strength was observed in the following order: no filler $>$ silica $>$ carbon black $>$ talc $>$ organically modified layered silicate. The talc loaded chloroprene rubber composite, chloroprene rubber- $\mathrm{T}$, showed a 
slower degradation rate and lower change in tensile strength than the silica and carbon black-loaded chloroprene rubber composites. The aspect ratio of talc was higher than silica and carbon black, which leads to a decrease in the oxygen diffusion rate. Compared to chloroprene rubber-organically modified layered silicate, chloroprene rubber- $\mathrm{T}$ showed a fast degradation rate and a large change in tensile strength because talc did not disperse on the nano-level and had a lower aspect ratio than organically modified layered silicate. Chloroprene rubber-organically modified layered silicate showed the lowest change in tensile strength $(-1.4 \mathrm{MPa})$. Compared to the initial state, the tensile strength of chloroprene rubber-organically modified layered silicate decreased approximately $10 \%$ after the thermal aging test. Chloroprene rubber-organically modified layered silicate showed the slowest degradation rate compared to the other fillers. Fig. 6 showed a change in elongation after the thermal aging test. Elongation was decreased after the thermal aging test. The change in elongation of chloroprene rubber-NF was $-248 \%$. Compared to the initial state, the elongation of chloroprene rubber-NF decreased approximately $41.3 \%$ after the thermal aging test. The change in elongation was observed in the following order: no filler $>$ silica $>$ carbon black $>$ talc $>$ organically modified layered silicate. Chloroprene rubber-organically modified layered silicate showed the lowest change in elongation $(-76 \%)$. Compared to the initial state, the elongation of chloroprene rubber-organically modified layered silicate decreased approximately $12.3 \%$ after the thermal aging test. chloroprene rubber-organically modified layered silicate showed the slowest degradation rate compared to the other fillers. The change in elongation showed a similar tendency to the change in tensile strength. Fig. 7 shows change in tear strength after the thermal aging test. The tear strength decreased after the thermal aging test. The change in tear strength of chloroprene rubber-NF was $-11.0 \mathrm{kN} / \mathrm{m}$. Compared to the initial state, the tear strength of chloroprene rubber-NF decreased approximately $45.8 \%$ after the thermal aging test. The change in tear strength was observed in the following order: no filler $>$ silica $>$ carbon black $>$ talc $>$ organically modified layered silicate. Chloroprene rubber-organically modified layered silicate showed the lowest change in tear strength, $-4.6 \mathrm{kN} / \mathrm{m}$. Compared to the initial state, the tear strength of chloroprene rubberorganically modified layered silicate decreased approximately $13.3 \%$ after the thermal aging test. Chloroprene rubberorganically modified layered silicate showed slowest degradation rate compared to other fillers. Fig. 8 shows the change in the compression set after the thermal aging test. The compression set deteriorated after the thermal aging test. The change in the compression set of chloroprene rubber-NF was $+11.6 \%$. Compared to the initial state, the compression set of chloroprene rubber-NF deteriorated approximately $31.4 \%$ after the thermal aging test. The change in compression set was observed in the following order: no filler $>$ silica $>$ carbon black $>$ talc $>$ organically modified layered silicate. Chloroprene rubber-organically modified layered silicate showed the smallest change in compression set $(+3.0 \%)$. Compared to the initial state, the compression set of chloroprene rubberorganically modified layered silicate deteriorated approxi- mately $9.3 \%$ after the thermal aging test. Chloroprene rubber-organically modified layered silicate had the slowest degradation rate, compared to the other fillers. Chloroprene rubber-organically modified layered silicate showed the slowest degradation rate, because the tortuous structure prevented oxygen diffusion.

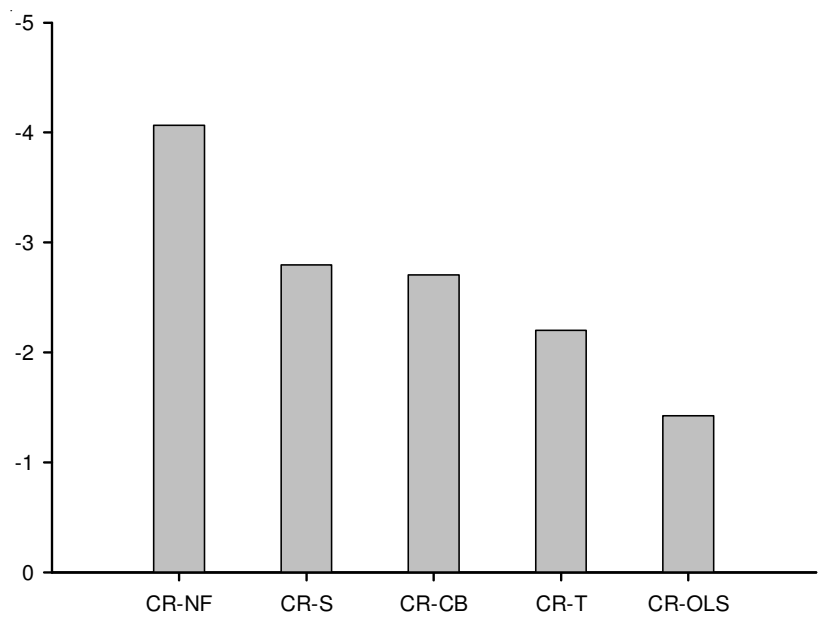

Fig. 5. Changes of tensile strength by filler type after thermal aging test

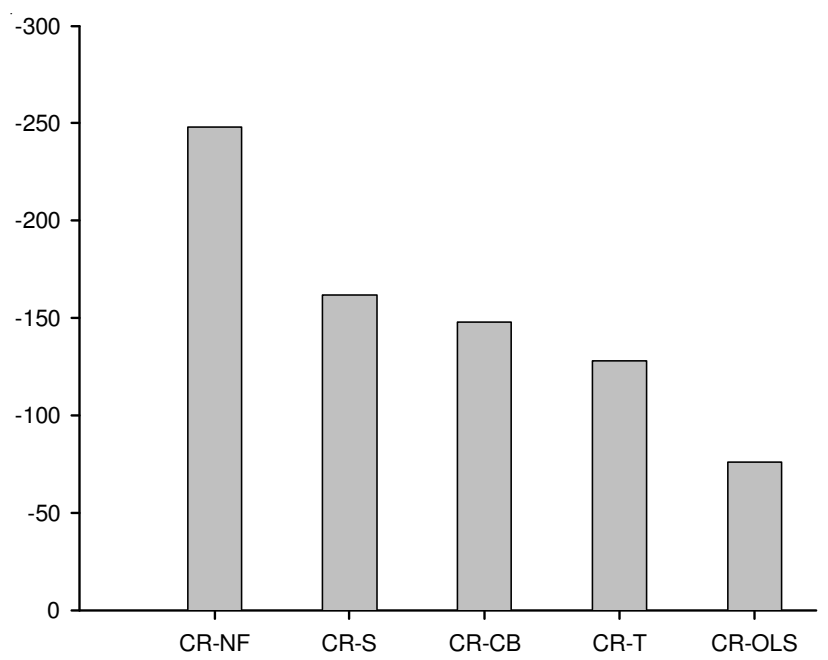

Fig. 6. Changes of elongation by filler type after thermal aging test

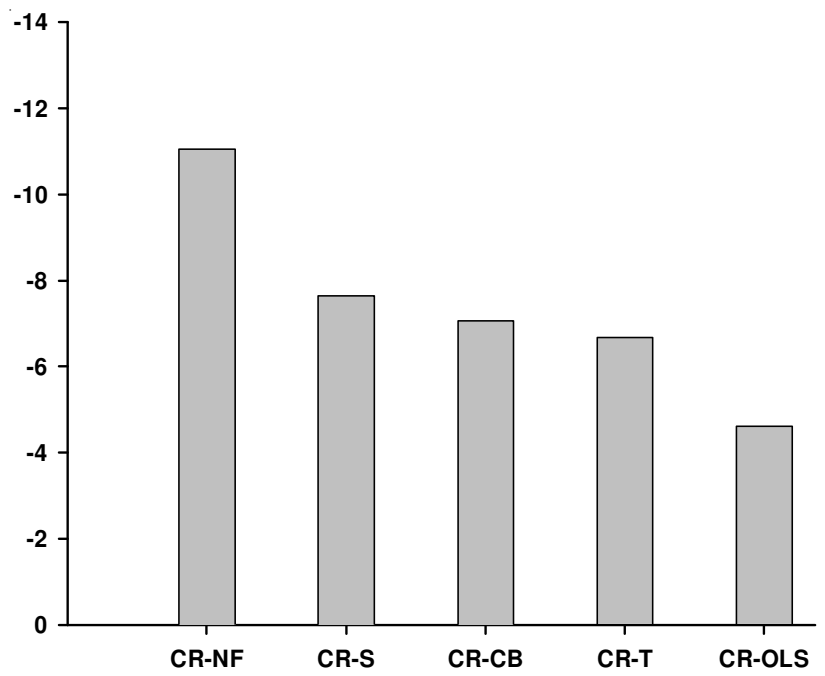

Fig. 7. Change of tear strength by filler type after thermal aging test 


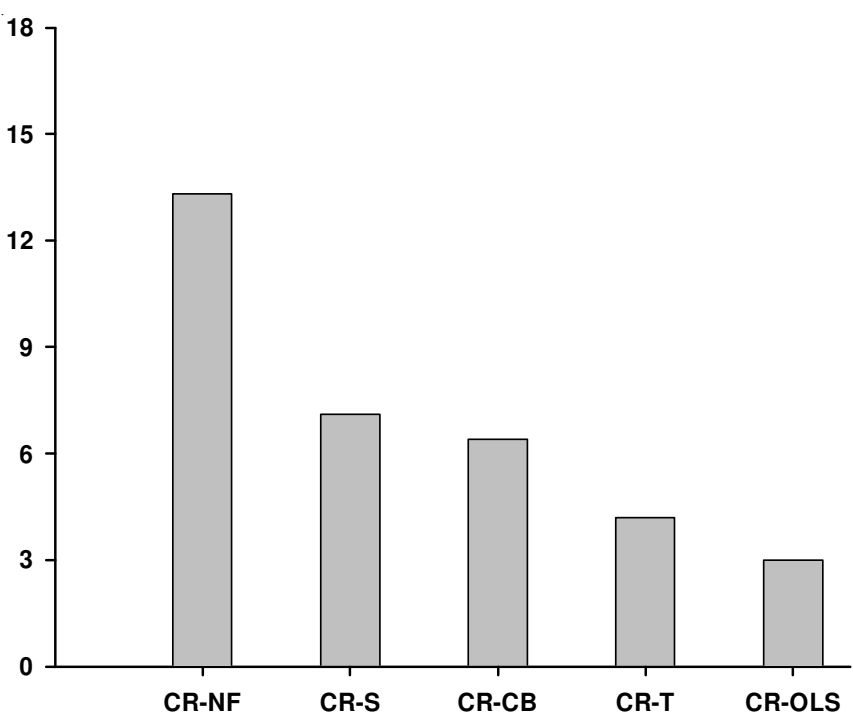

Fig. 8. Change of compression set by filler type after thermal aging test

Modulus profile after thermal aging test: Fig. 9 shows the modulus profile of chloroprene rubber-NF and chloroprene rubber-organically modified layered silicate. The 40-60\% position showed the lowest compressive modulus and the $0 \%$ and $100 \%$ position showed the highest $10 \%$ compressive modulus because degradation of the chloroprene rubber composites was dependent on oxygen diffusion. Therefore, the level of oxygen diffusion differed according to the position and the specimen surface showed a faster degradation rate than the center of the specimen. Chloroprene rubber-organically modified layered silicate showed an $88 \mathrm{~N}$ deviation in modulus according to the position, but chloroprene rubber-NF showed a $196 \mathrm{~N}$ deviation in modulus. At the $40 \%$ and $60 \%$ position, chloroprene rubber-organically modified layered silicate showed a lower $10 \%$ compressive modulus than chloroprene rubber-NF because chloroprene rubber-organically modified layered silicate formed a tortuous structure by the intercalation of organically modified layered silicate, leading to a lower oxygen diffusion rate and slower degradation rate than chloroprene rubber-NF.

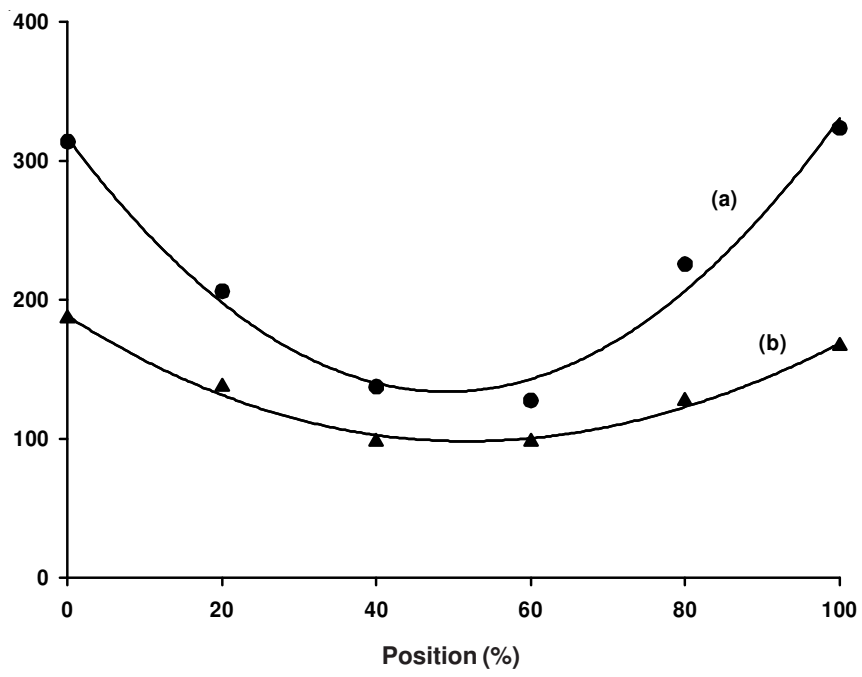

Fig. 9. Modulus profile for $2 \mathrm{~mm}$ thickness chloroprene rubber composites after thermal aging test; (a) chloroprene rubber-NF, (b) chloroprene rubber-organically modified layered silicate
Oxygen permeability of chloroprene rubber composites: Fig. 10 shows results of oxygen permeability. The oxygen permeability of chloroprene rubber-NF was 310 $\mathrm{cm}^{3} / \mathrm{m}^{2}$ day·atm. The oxygen permeability decreased with increasing filler loading because oxygen cannot permeate to the filler particles and the dispersion of the filler prevents oxygen diffusion. The oxygen permeability was observed in the order: no filler $>$ carbon black $>$ silica $>$ talc $>$ organically modified layered silicate. Chloroprene rubber-organically modified layered silicate showed the lowest oxygen permeability $\left(90 \mathrm{~cm}^{3} / \mathrm{m}^{2}\right.$ day.atm). Compared to chloroprene rubber$\mathrm{NF}$, the oxygen permeability of chloroprene rubber-organically modified layered silicate was approximately $71 \%$ lower. The oxygen permeability is determined by the shape of the filler and dispersion state. A high aspect ratio and welldispersed filler could form a tortuous structure and can have low oxygen permeability. Therefore, even if chloroprene rubber-T had lower mechanical properties than chloroprene rubber-S and chloroprene rubber-CB, chloroprene rubber- $\mathrm{T}$ showed lower oxygen permeability and a slower degradation rate than chloroprene rubber-S and chloroprene rubber-CB. By intercalating the organically modified layered silicate layers to the chloroprene rubber matrix, chloroprene rubber-organically modified layered silicate could form a highly improved tortuous structure, which leads to the lowest oxygen permeability and slowest degradation rate.

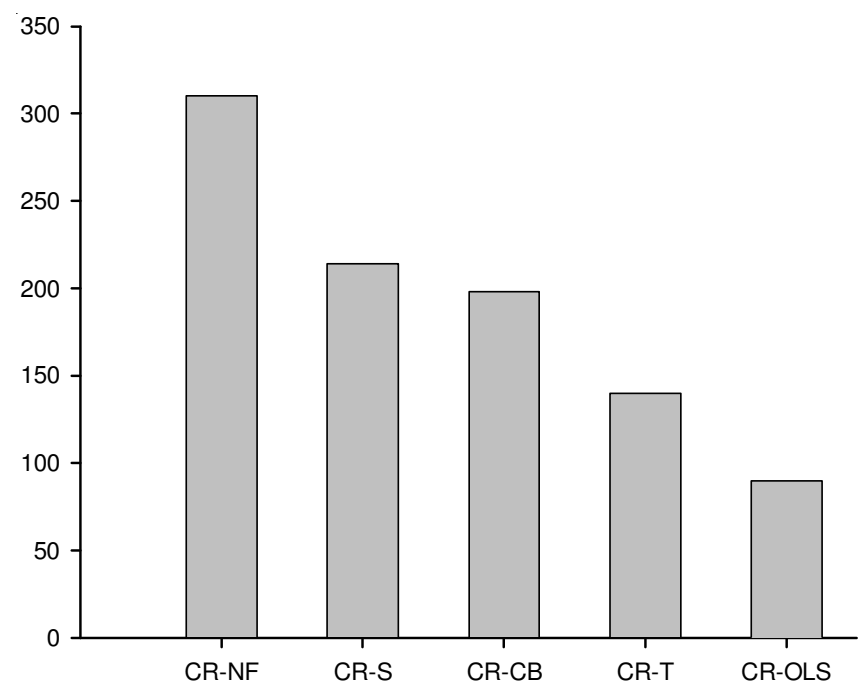

Fig. 10. Oxygen permeability of chloroprene rubber (CR) composites by filler type

\section{Conclusion}

The chloroprene rUBBER/organically modified layered silicate nanocomposite was prepared using the melt intercalation method. XRD confirmed the dispersion of organically modified layered silicate. Comparing to pure organically modified layered silicate, the basal space of the chloroprene rubber/organically modified layered silicate nanocomposite increased from 2.1 $\mathrm{nm}$ to $4.2 \mathrm{~nm}$ and the XRD peak shifted from $3.96^{\circ}$ to $2.35^{\circ}$ 20. XRD also confirmed that the organically modified layered silicate layers were intercalated into the chloroprene rubber matrix. Compared to the conventional filler loaded composites, chloroprene rubber-organically modified layered silicate had 
high mechanical properties. Chloroprene rubber-organically modified layered silicate showed a 28, 43 and $43 \%$ improvement in tensile strength, tear strength and compression set, respectively, compared to chloroprene rubber-NF. The change in mechanical properties after the thermal aging test were dependent on the aspect ratio and dispersion state of the filler. The aspect ratio of talc and organically modified layered silicate were higher than the others, which leads to a small change in mechanical properties and a slow degradation rate. As organically modified layered silicate was dispersed on the nano-level, chloroprene rubber-organically modified layered silicate showed the smallest change in mechanical properties. In the modulus profile, chloroprene rubber-organically modified layered silicate showed a smaller deviation of the modulus with position and a lower $10 \%$ compressive modulus than chloroprene rubber-NF. Intercalation of the organically modified layered silicate layers to the chloroprene rubber matrix led to the formation of a tortuous structure. The tortuous structure hindered oxygen diffusion and decreased the degradation rate. An analysis of the oxygen permeability confirmed that chloroprene rubber-organically modified layered silicate formed a tortuous structure.

\section{REFERENCES}

1. R.P. Brown, Practical Guide to the Assessment of the Useful Life of Rubbers, Rapra Technology Limited, UK (2001).

2. J. Wise, K.T. Gillen and R.L. Clough, Radiat. Phys. Chem., 49, 565 (1997).

3. M. Celina, K.T. Gillen and R.A. Assink, Polym. Degrad. Stab., 90, 395 (2005).

4. K.T. Gillen, J. Wise and R.L. Clough, Polym. Degrad. Stab., 47, 149 (1995).

5. J. Wise, K.T. Gillen and R.L. Clough, Polymer, 38, 1929 (1997).

6. K.T. Gillen, R. Bernstein and M. Celina, Polym. Degrad. Stab., 87, 335 (2005).

7. K.T. Gillen, M. Celina and R. Bernstein, Polym. Degrad. Stab., 82, 25 (2003).

8. J. Wise, K.T. Gillen and R.L. Clough, Polym. Degrad. Stab., 49, 403 (1995).

9. K.T. Gillen and M. Celina, Polym. Degrad. Stab., 71, 15 (2001).

10. R. Bernstein and K.T. Gillen, Polym. Degrad. Stab., 94, 2107 (2009).

11. M. Celina, J. Wise, D.K. Ottesen, K.T. Gillen and R.L. Clough, Polym. Degrad. Stab., 68, 171 (2000).

12. M. Pluta, A. Galeski, M. Alexandre, M.A. Paul and P. Dubois, J. Appl. Polym. Sci., 86, 1497 (2002).

13. A. Uksuki, A. Tukigase and M. Kato, Polymer, 43, 2185 (2002).

14. A.B. Morgan and W.G. Jeffrey, J. Appl. Polym. Sci., 87, 1329 (2003).

15. S. Varghese and J. Karger-Kocsis, Polymer, 44, 4921 (2003).

16. L.Q. Zhang, Y.Z. Wang, Y.Q. Wang, Y. Sui and D.S. Yu, J. Appl. Polym. Sci., 78, 1873 (2000).

17. Y.R. Liang, Y.Q. Wang, Y.P. Wu, Y.L. Lu, H.F. Zhang and L.Q. Zhang, Polym. Testing, 24, 12 (2005) 